\title{
Co-Infection of Dengue Fever with COVID-19 in a Child with MIS-C
}

\author{
Vinod H. Ratageri ${ }^{1}$ (D) Gayatri R. Pawar ${ }^{1} \cdot$ Nikhil G $^{1} \cdot$ Sara S. George ${ }^{1}$ \\ Received: 22 December 2020 / Accepted: 8 February 2021/ Published online: 2 March 2021 \\ (C) Dr. K C Chaudhuri Foundation 2021
}

To the Editor: We are in the midst of an unprecedented global pandemic of coronavirus disease 2019 (COVID-19). In children of late we are seeing a peculiar condition called multisystem inflammatory syndrome (MIS-C) [1]. Worryingly, some diseases like dengue, rickettsial fever mimic the clinical manifestations of COVID-19. There are reported cases of coinfection of dengue with COVID-19 [2], and also false positive dengue antibodies in COVID-19 cases [3]. All these are reported in adults. Herein, we report a child with MIS-C and co-infected with dengue virus.

An 8-y-old male child, presented with acute onset high grade fever of $8 \mathrm{~d}$ duration, abdominal pain, and vomiting. No history of cough/cold, hurried breathing, chest-indrawing, joint swelling/redness, bleeding manifestations. Examination revealed bilateral conjuctival congestion, facial puffiness, and erythematous macular rashes on palms and soles and tender hepatomegaly. Other systems were unremarkable except variable heart rate. Complete blood count (CBC) with maximum and minimum counts was as follows, leukocyte counts $[12,900 / \mathrm{cmm}$ (P: $43 \%$, L: $43 \%$ ) and $7700 / \mathrm{cmm}$ (P: $78 \%$, L: $15 \%)]$, platelets $(411,000 / \mathrm{cmm}$ and $96,000 /$ $\mathrm{cmm}$ ) and hematocrit (29.9\% and $25.3 \%$ ). Reverse transcription polymerase chain reaction (RT-PCR) for SARS-CoV-2 was positive and serology for COVID-19 showed raised immunoglobulin $\mathrm{G}$ ( $\mathrm{IgG}$ ) antibody titer. Inflammatory markers were raised [C-reactive protein $(\mathrm{CRP})>90 \mathrm{mg} / \mathrm{dL}$, ferritin $157 \mathrm{ng} / \mathrm{mL}$, lactate dehydrogenase (LDH) $257 \mathrm{U} / \mathrm{L}$, D-dimer $2793 \mathrm{ng} / \mathrm{mL}$ ]. Ultrasound imaging of the abdomen showed minimal ascites with hepatomegaly. 2D echo showed globally hypokinetic left ventricular (LV) dysfunction with an ejection fraction of $30 \%$. Dengu immunoglobulin $M$

Vinod H. Ratageri

ratageri@rediffmail.com

1 Department of Pediatrics, Karnataka Institute of Medical Sciences, Hubli 580021, Karnataka, India
(IgM) was positive by $\operatorname{IgM}$ antibody-capture enzymelinked immunosorbent assay (MAC-ELISA).

Child improved with intravenous (IV) immunoglobulin therapy $(2 \mathrm{~g} / \mathrm{kg})$. As vitals were stable, child was managed with only oral fluids. Heart rate variability normalized, repeat 2D echo showed ejection fraction of $45 \%$ and $60 \%$ during followup and inflammatory markers reduced to normal.

MIS-C was considered in our child as the child met the WHO criteria. Dengue was considered because of presence of rash, minimal ascites, hepatomegaly, thrombocytopenia and as we are in epidemic. Ideally dengue confirmation was by RT-PCR; however, as per Ministry of Health and Family Welfare Department (MHFWD), Govt. of India [4], even dengue IgM by MAC-ELISA will be considered as confirmed case. As clinical features overlap, children should be tested for both viruses in India.

\section{Declarations}

Conflict of Interest None.

\section{References}

1. Kaushik A, Gupta S, Sood M, Sharma S, Verma S. A systematic review of multisystem inflammatory syndrome in children associated with SARS-CoV-2 infection. Pediatr Infect Dis J. 2020;39(11): e340-6.

2. Yan G, Lee CK, Lam LTM, et al. Covert COVID-19 and falsepositive dengue serology in Singapore. Lancet Infect Dis. 2020;20(5):536.

3. Harapan H, Ryan M, Yohan B et al. Covid-19 and dengue: double punches for dengue- endemic countries in Asia. Rev Med Virol. 2020; e2161.

4. Case definitions- L form, Manuals \& Guidelines, Integrated Disease - IDSP. Available at: https://idsp.nic.in/index1.php?page=1\&ipp= $25 \&$ lang $=1 \&$ level $=1 \&$ sublinkid $=5821 \&$ lid $=376$. Accessed $7^{\text {th }}$ Jan 2021.

Publisher's Note Springer Nature remains neutral with regard to jurisdictional claims in published maps and institutional affiliations. 